\title{
Can we send patients with small pneumothorax post drain removal home?
}

\author{
Sanjeet SA Singh", Karim Morcos, Alan JB Kirk \\ From World Society of Cardiothoracic Surgeons 25th Anniversary Congress, Edinburgh \\ Edinburgh, UK. 19-22 September 2015
}

\section{Background/Introduction}

Pneumothorax can be a complication following chest drain removal. In thoracic surgery, access to the pleural cavity involves a pleurotomy. A chest drain is inserted to allow re-expansion of the lungs post-pleurotomy. This also prevents a tension pneumothorax. Some patients have a residual pneumothorax post-chest drain removal noted on chest radiography. Rates of pneumothorax post chest drain removal vary with figures quoted at 9.3-13.6\%. The majority of these are barely perceptible or small $(<1 \mathrm{~cm}$ from pleural line to the apex of the hemithorax). Is it safe to discharge these patients home?

\section{Aims/Objectives}

To assess if it is safe to send patients with small pneumothorax home post chest drain removal

\section{Method}

A retrospective observational study was done at our unit over a 6-month period. All patients had chest drains postoperatively and were discharged if there were no air leaks and the patients were stable. A repeat CXR was obtained during routine follow up in 6 weeks' time. Patients with pneumonectomies and permanent thoracostomies were excluded from the study.

\section{Results}

There were 158 patients in the study. The mean age of the patients was 59.7 years (SD: 16.6). All patients were asymptomatic at the time of discharge and none required further intervention in other hospitals with regards to their pneumothorax. There were 29 (18.4\%) patients who were discharged with small residual pneumothorax ( $<1$ rib space) visible on CXR. At 6 weeks of

Golden Jubilee National Hospital, Clydebank, Dumbartonshire, G81 4DY, UK follow up, 7 (4.4\%) patients had visible pneumothorax on their CXR with no radiological or symptomatic worsening.

\section{Discussion/Conclusion}

This study found that it was safe to discharge asymptomatic patients with a small pneumothorax provided they are haemodynamically stable. Our study shows that $76 \%$ of these patients will have no residual pneumothorax in 6 weeks' time and the remaining $24 \%$ will continue to be asymptomatic with no radiological worsening of their pneumothorax.

Published: 16 December 2015

doi:10.1186/1749-8090-10-S1-A191

Cite this article as: Singh et al:: Can we send patients with small pneumothorax post drain removal home? Journal of Cardiothoracic Surgery 2015 10(Suppl 1):A191.
Submit your next manuscript to BioMed Central and take full advantage of:

- Convenient online submission

- Thorough peer review

- No space constraints or color figure charges

- Immediate publication on acceptance

- Inclusion in PubMed, CAS, Scopus and Google Scholar

- Research which is freely available for redistribution
() Biomed Central 